Research Article

\title{
Risk-Optimized Design of Production Systems by Use of GRAMOSA
}

\author{
Michael Lütjen and Abderrahim Ait Alla \\ Bremer Institut für Produktion und Logistik GmbH at (BIBA), The University of Bremen, 28359 Bremen, Germany \\ Correspondence should be addressed to Michael Lütjen; ltj@biba.uni-bremen.de
}

Received 31 January 2014; Accepted 12 February 2014; Published 20 March 2014

Academic Editor: Hamid R. Karimi

Copyright (C) 2014 M. Lütjen and A. Ait Alla. This is an open access article distributed under the Creative Commons Attribution License, which permits unrestricted use, distribution, and reproduction in any medium, provided the original work is properly cited.

Today production and logistic systems are getting more complex. This is a problem which the planning and design of such systems have to deal with. One main issue of production system development in series production is the planning of production processes and systems under uncertainty. New and existing production technologies are often not fully adoptable to new products. This is why some of the main characteristics, like, for example, cost, time, or quality, are not definable at the beginning. Only value ranges and probabilities can be estimated. However, the adaptation process is controllable, which means that the adaptation results are depending on the existing development budget and its resources. This paper presents an approach for the optimized allocation of development resources regarding the adaptation risks of production technologies and processes. The modeling concept GRAMOSA is used for integrated modeling and discrete event-based simulation of the aspired production system. To this end a domain-specific modeling language (DSML) is applied. The further risk-based analysis of the simulation results and the optimized allocation of the development budget are done by use of mathematical optimization.

\section{Introduction}

The planning and design of production systems are a challenging task. Production systems are becoming more and more complex and less predictable $[1,2]$. In addition to the existing objectives for efficient production of a given set of products, new concepts of changeable manufacturing have to be considered [3]. Flexible and changeable production systems are needed to face the challenges of a global and dynamic market, but this leads directly to an increased complexity [4]. A design concept of a production system has to consider potential developments, which makes the difficult task of production system development even more difficult. The only given approach to handle such complexity is the use of digital engineering solutions, like, for example, the concept of digital factory [5]. Based on the concept of model-driven engineering, the process of production system development is supported by specific IT solutions. These should allow us to model, simulate, and visualize the aspired production system in a digital and virtual way [6]. The concept of digital factory is a promising approach to overcome the needs for a more efficient production system development. At the moment, however, only small domains, like, assembly lines in automotive industry, are able to be planned by latest software concepts [7]. Therefore, a lot of research is needed to make such software concepts more flexible and applicable to other domains. This paper addresses the introduction of risk management in the process of production system development based on a perspective of integrated manufacturing and logistics planning as part of logistics engineering. Thereby, the development risks of the aspired manufacturing and production processes will be assessed and considered in allocation of development budget and resources. A literature review is given in the second chapter, while the third chapter deals with the concept of model-driven logistics engineering using GRAMOSA. The modeling concept GRAMOSA is explained to this end, and a use case of a metalworking production process is defined. In the fourth chapter, the mathematical optimization of the risk-based allocation problem of development budgets and resources is presented. A summary and outlook are given in the fifth chapter. 


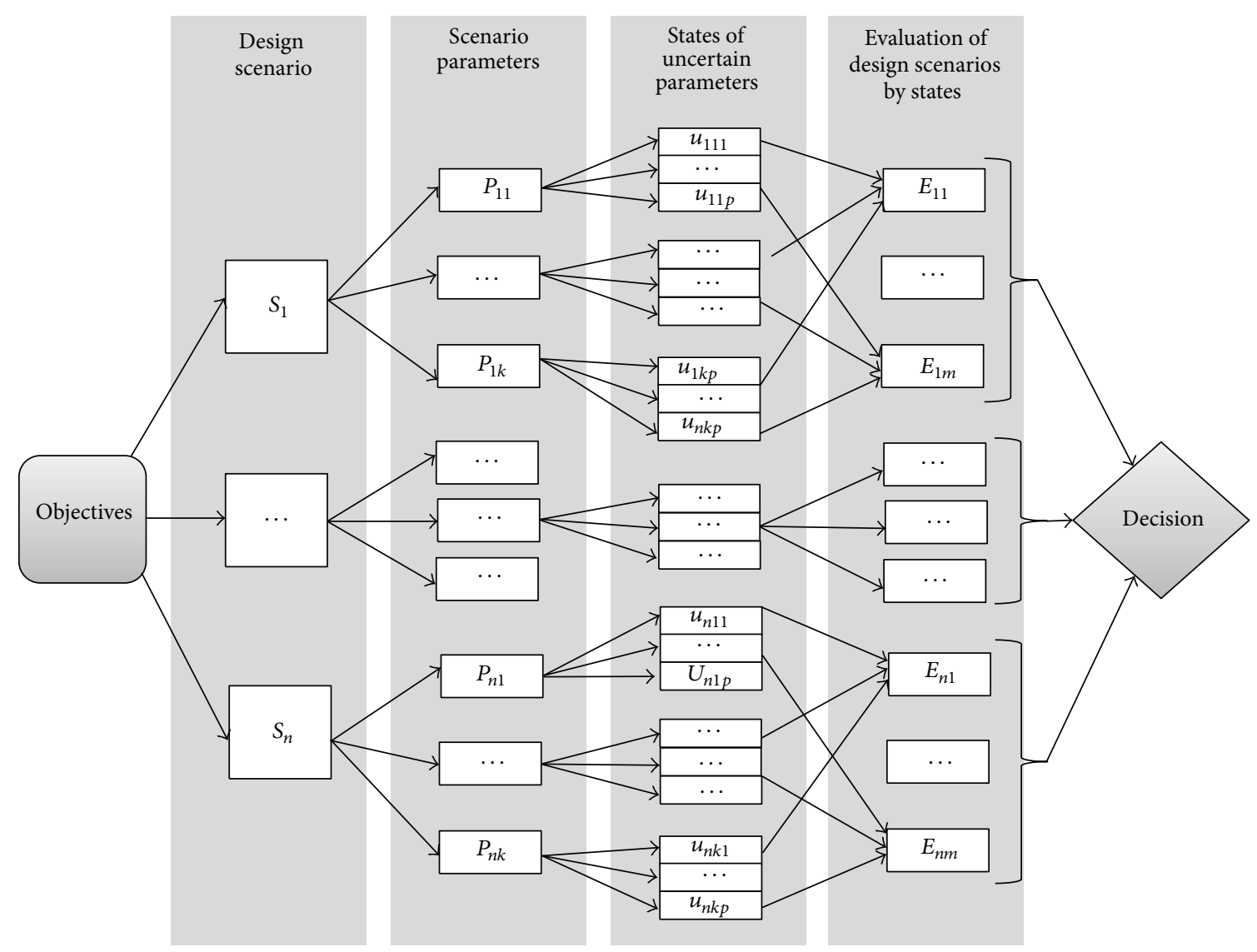

FIgURE 1: Production system development under uncertainty; compare [8].

\section{Choice under Uncertainty in Production System Development}

In general, the early integration of risk analysis in the production system development process has the potential to eliminate or reduce ramp-up problems and production disturbances in a later phase of production system life cycle [10]. Thereby, the handling of uncertainty is essential for the riskbased evaluation of system alternatives. Münster presents an approach of decision under uncertainty in the case of different design scenarios [8]. Thereby, scenario parameters are defined for each design scenario (Figure 1). The next step is to determine states of uncertain parameters, which can be used to evaluate the design scenarios by states. During the last step, the decision can be made by analyzing and comparing the different design scenarios, for example, by mean values and variances. In principle, also probability distributions can be used; however, in practice, the estimation of different probable states is very difficult, even for domain experts [11].

The development of production systems under uncertainty is a big challenge and concerns different levels of production. Inman et al. define the following levels of production system development [12]:

(i) supply chain;

(ii) production planning; (iii) system layout;

(iv) equipment selection;

(v) production management.

Today, the level of supply chain is very important for the design of production systems regarding decisions about capacity extensions. Kostin et al. present an approach of the strategic planning of an integrated bioethanol-sugar supply chain under uncertainty in the demand [13]. A multiscenario mixed-integer linear programming (MILP) problem is developed that seeks to optimize the expected performance of the supply chain under several financial risk mitigation options. The level of production planning is relevant for process planning. The latter is the systematic determination of production steps to manufacture a product. In order to evaluate a specific process design, it is necessary to get detailed data for such production steps, like, for example, turning or milling, in order to determine the process parameters and their uncertainties. Heilala et al. present a design approach of production systems, which is oriented to sustainability [14]. To this end, they integrated methods for the calculation of energy efficiency and $\mathrm{CO} 2$ emissions into factory simulation software. The design of a system layout is still a challenging task, because nowadays the aspects of changeability have to be considered [3]. This includes flexibility, complexity, entropy, and robustness. According to Inman et al., the manufacturing 

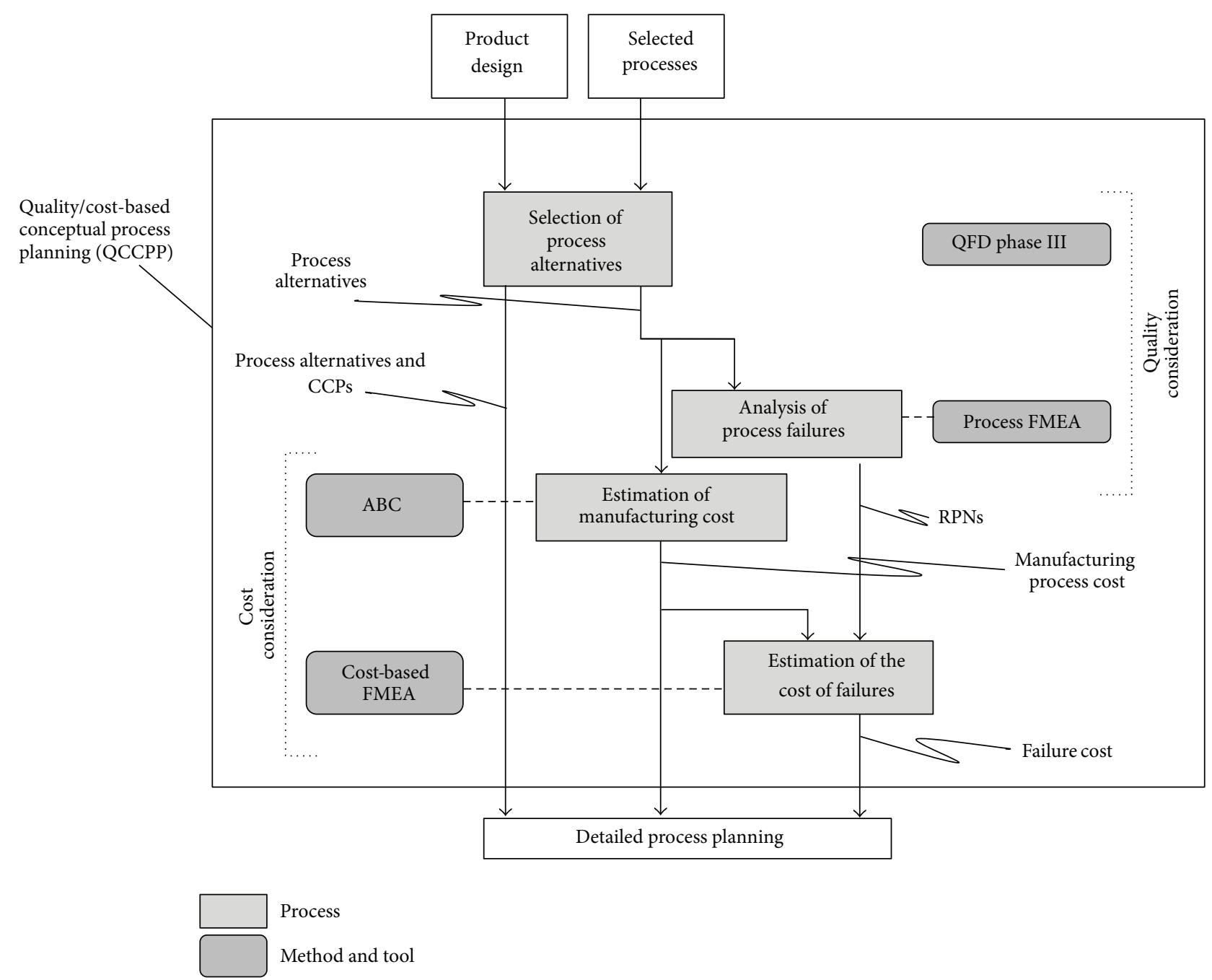

FIGURE 2: Selection process of design scenarios regarding cost and quality [9].

flexibility is the capability of building different products in one system without the need for new machines [12]. Complexity and higher entropy are main issues due to the globalization and smaller lot sizes, while robustness is the characteristic of dealing with fluctuations in operations without decreasing the product quality. Another level of production system design is the selection of equipment. In general, better machines cost more money, but they are faster and produce more parts with fewer failures. However, the process and ressource parameters have to be estimated by domain experts, for what reason all parameters include uncertainties. The last level of production system design is the production management. Production management has a high impact on product quality and equipment availability by organizing, for example, the maintenance management and implementing lean philosophies [12]. Due to the fact that the production management influences the system performance indirectly, it is very difficult to estimate costs and process reliabilities as well as product qualities. Nevertheless, there is a need to integrate such factors to production system design. For this reason, Hassan et al. developed a selection process of design scenarios regarding cost and quality [9]. Based on a given product design and an aspired process chain, some methods of quality management (QFD, FMEA, etc.) and costing are applied in order to estimate manufacturing costs, quality failures, and quality costs (Figure 2).

Next to cost and quality, various key performance indicators (KPI) exist, which have to be measured and which can include uncertainties. Hon presents a study which considers cost performance and quality performance measures as well as time, flexibility, and productivity performance measures [15]. Thereby, the overall lead time is one of the most relevant KPI, which exists for evaluation 9 of manufacturing and production systems. In process planning the estimation of an overall lead time is very difficult because of high impacts due to production management, like, production planning and control strategies [16].

\section{Model-Driven Logistics Engineering by Use of GRAMOSA}

The production system design is faced with numerous challenges that necessitate a detailed depiction of the production 


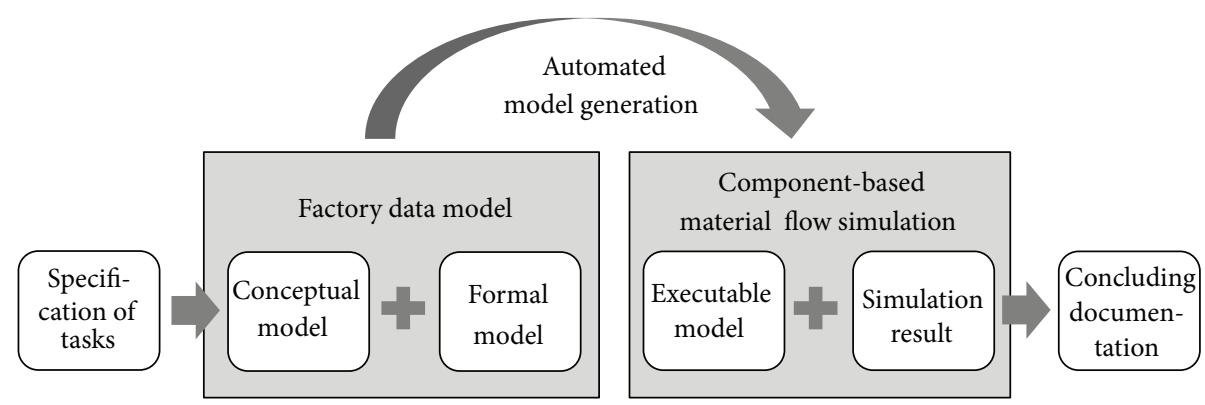

FIGURE 3: Automatic generation of simulation models from factory data models.

processes and material flows in order to ensure the proper communication of planning content [17]. Thereby, conceptual models can help to collect and structure the data by graphical modeling. The objective of model-driven logistics engineering is to transform automatically such conceptual models of production systems into executable simulation models (Figure 3). This would be beneficial due to the fact that manual model transformation costs a lot of time and is source for transformation errors. Therefore, automated model generation is one of the main issues in context of digital factory. It has already been discussed in scientific communities over a few years [18-20].

Despite promising scientific applications and prototypes, the automated generation of models has not yet been able to prevail in an industrial context [21]. Thereby, the main issues are the incomplete semantics of general purpose modeling languages (GPMLs). Sometimes, the description of domain specific semantics by use of general purpose modeling languages, like, UML, is too complex or just impossible. Therefore, domain-specific modeling languages (DSMLs) can be developed, which are modeling languages whose purpose is to represent concepts efficiently from a particular domain, like, financial services, production, and logistics [22]. The application of DSMLs means to simplify the use and to increase the model accuracy. Key elements, semantics, and constraints of the domain are defined precisely in the metamodel and can be used by domain experts to express the system behavior more intuitively [23]. At the following, the GRAMOSA modeling concept is presented, which contains a domain-specific modeling approach in order to describe complex production processes and systems [24].

3.1. Material Flow Oriented Process Modeling. The idea of the GRAMOSA modeling concept is to realize a process modeling approach, which represents control flows as well as material flows. Additionally, the process control shifts from process sequences to process steps. Encompassed by the integrated modeling of control and material flow, this will allow us to model production processes and systems very precisely. The modeling concept GRAMOSA uses four basic functions in order to control order/batch generation, order release, dispatching, and routing. The idea is to integrate all four control functions into the modeling concept. This is realized by adding these functions primarily to the trigger and order object (Figure 4).
The trigger has different activation rules, which are related to the activation event. In the case of a process-driven activation, the order trigger is connected to a process unit and different process events (start, finish, etc.) can be used for the activation (Figure 5). In a time-driven activation the trigger is connected to the time releaser. In a stock-driven activation, the order activator is connected to a buffer and several different rules can be formulated for the activation on the bases of minimum and maximum stocks. Additionally, the material flow condition can be specified by the connection with a material flow object. Thus, for example, in the case of mixed buffers, signals can be defined for certain material flow objects. After activation, the selection rule is processed. The selection rules define how the routing decision is made, while the process call rule defines how many process calls are executed. Amongst other things, the order object defines whether the process calls should be grouped into a batch or processed individually. As mentioned before, the order "dispatching" is realized by setting the dispatching rule for the organization unit. With the use of basic control functions, it is possible to implement the well-known control strategies, such as Conwip and Kanban.

GRAMOSA uses symbols from UML-class diagrams in order to apply regular UML tools for editing, but the syntax is completely new. GRAMOSA, in particular, is characterized by the use of fixed connection sequences. Concerning the material flow, the sequence is as follows: buffer (input), material flow object (input), process, material flow object (output), and buffer (output). This means that material flow objects must not exist without connection to the buffer and the process. The same applies to control flow. Activator element, trigger, order, and process are a fixed element connection sequence. Thereby, the trigger can have more than one order to realize routing decisions.

3.2. Description of the Software Concept. The software concept makes use of a central database solution for the management of all modeling information in MS Access. An MS Access integrated graphic user interface enables the user to manage planning scenarios and carry out modeling via a tree structure. The yEd Graph Editor is used for the graphic model representation: the model view can be exported from the MS Access application and shown in the yEd Graph Editor by use of GraphML-Format (Figure 6).

The GraphML-Format is a free file format based on XML, which offers a platform independent representation of 


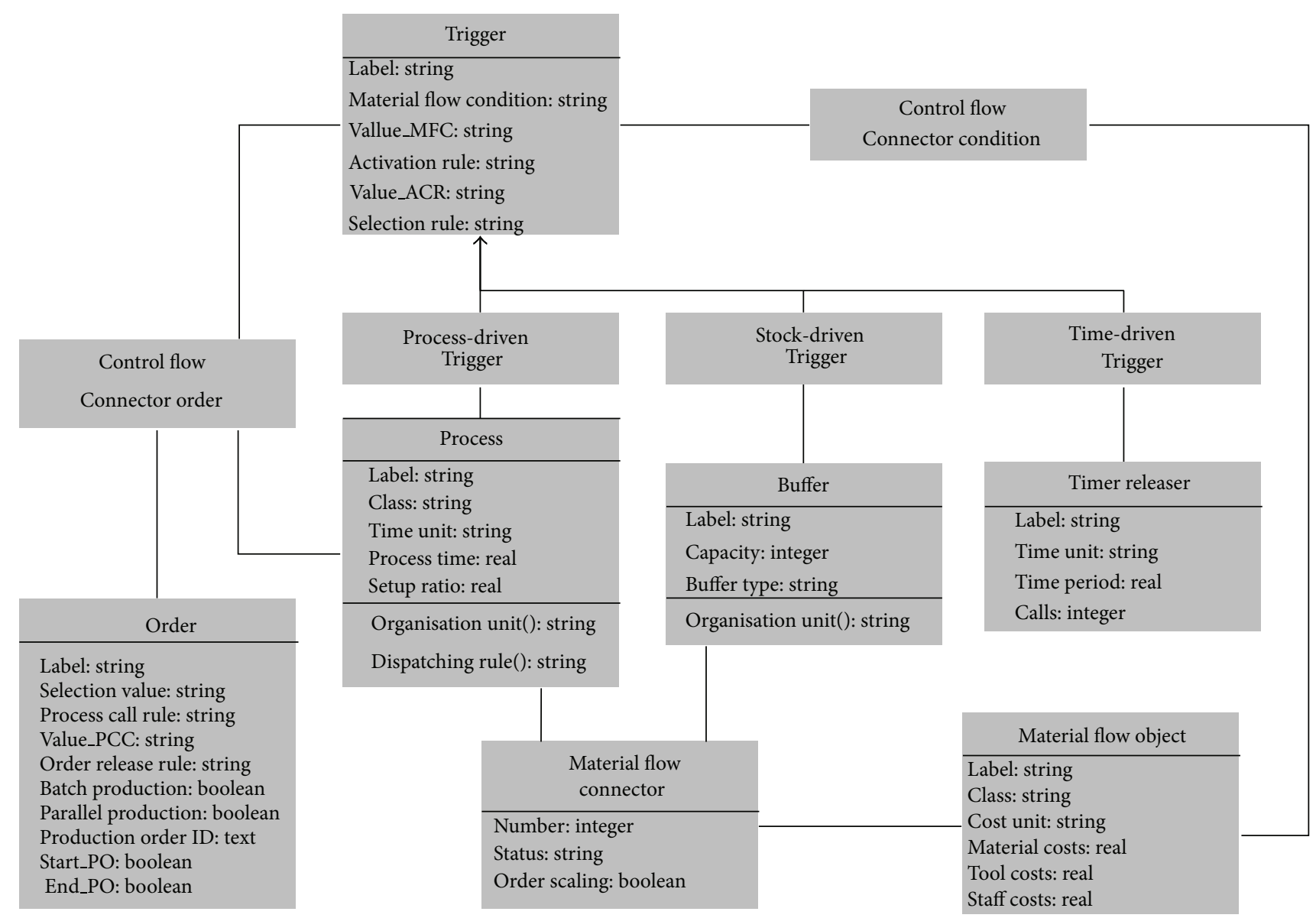

FIgURE 4: Metamodel of material flow oriented process modeling concept.

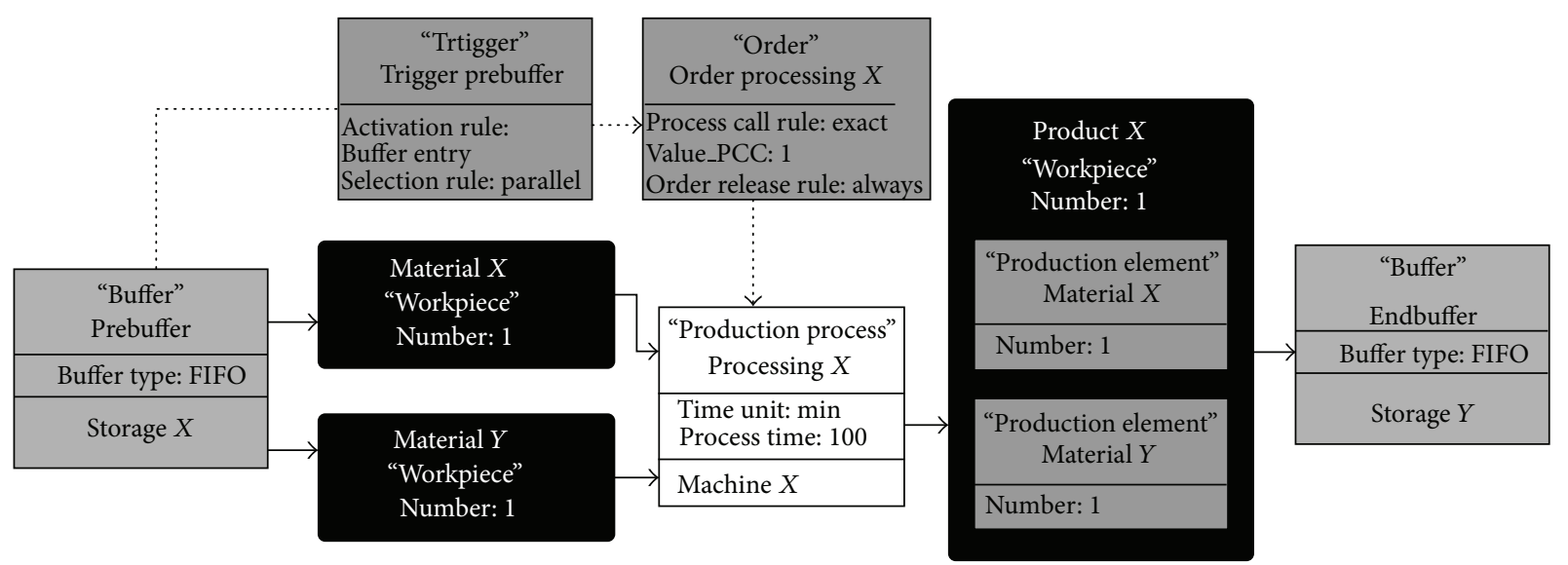

FIGURE 5: Example of material flow oriented process modeling.

graphs. The model structure can be analyzed directly in MS Access. A static dimensioning of the production concept can be achieved by exporting the manufacturing concept to MS Excel. The interface between MS Access and Tecnomatix Plant Simulation is implemented through prepared text tables. In principle, implementation solutions are conceivable that directly access the MS Access database from the simulation environment via ODBC. However, due to the complex database structure and elaborate filter operations for the scenario selection, this approach was given up. It can be implemented better in MS Access. In addition, the prepared text tables can be used as input data for other simulations. In order to realize fully automatic model generation, the structure of the simulation environment is individually programmed. The actual simulation model generation takes place in Tecnomatix Plant Simulation and is entirely automatic. 


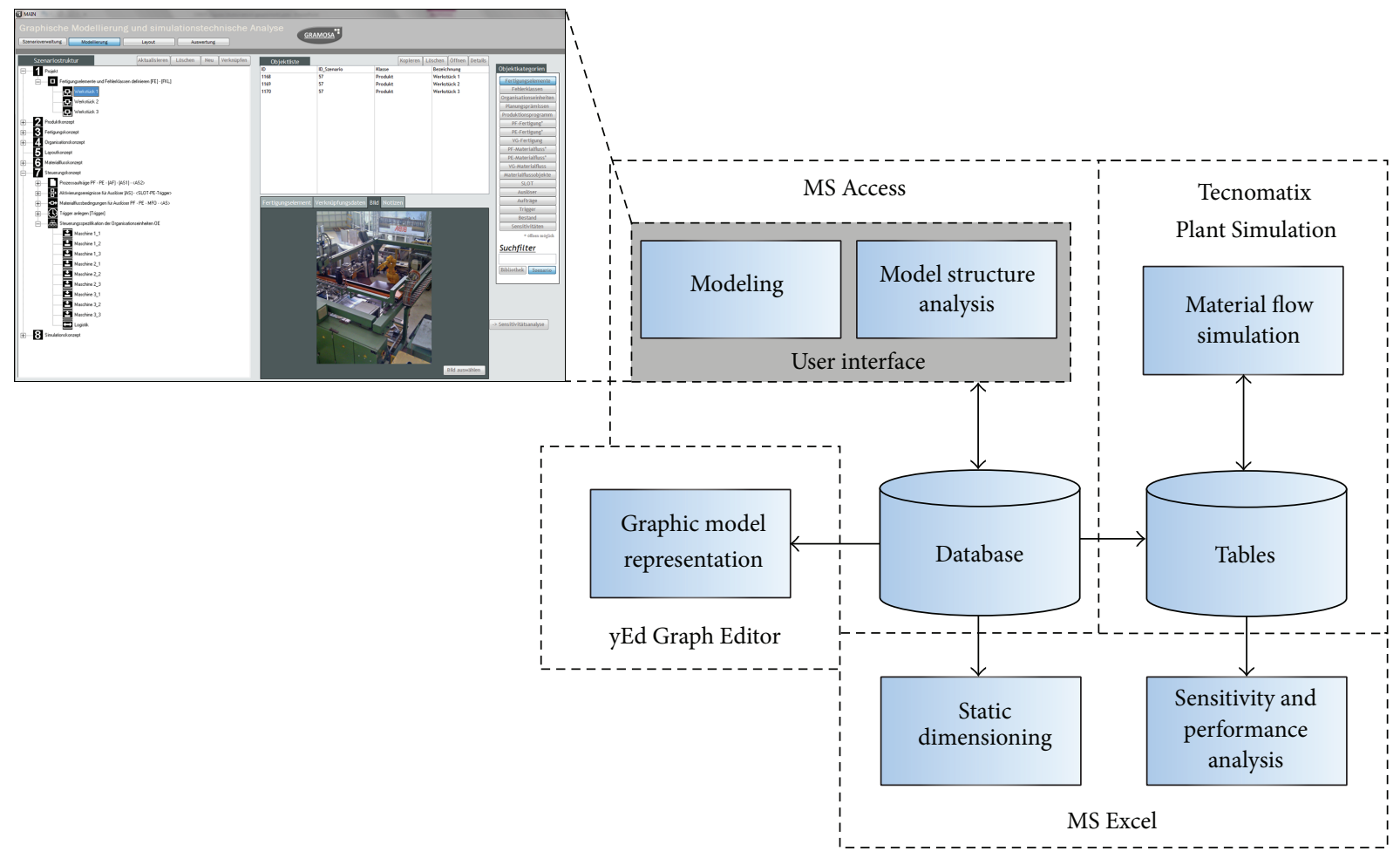

FIGURE 6: GRAMOSA software concept and prototypical user interface.

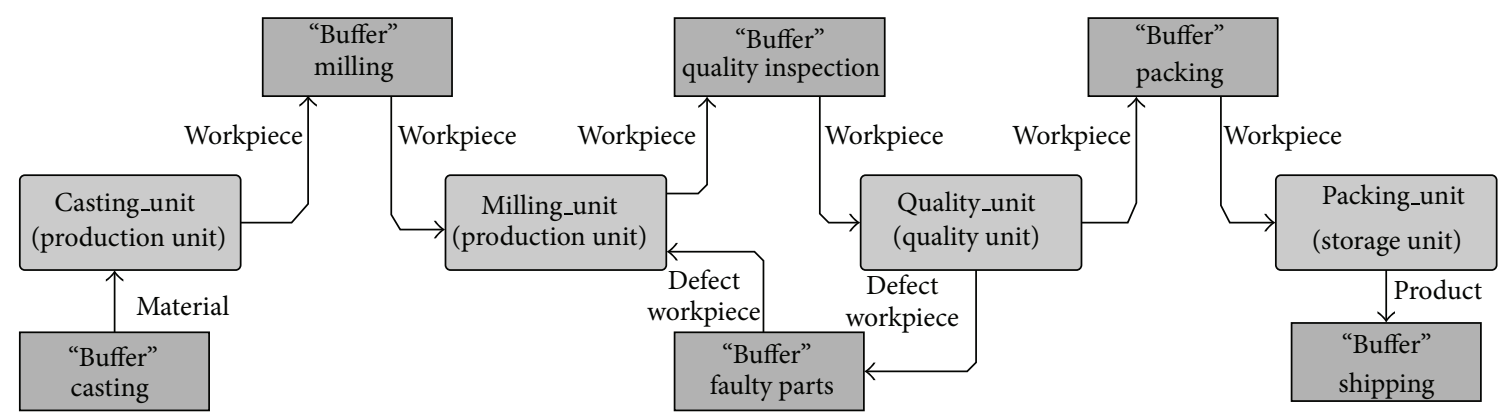

FIGURE 7: Material flow scheme of metalworking process by consideration of rework.

Manual interventions are only necessary when new process and con-trol logics are added and they thus need to be newly implemented. In the simulation environment, the strict separation of control and material flow is noticeable. The order control is responsible for observing the production system and releasing the order by obeying the release rule. The calculation of key performance indicators, like, for example, lead times and costs, is implemented in order to evaluate different parameter and resource settings.

\subsection{Sample Use Case: Metalworking Process by Consideration} of Rework. In order to show the feasibility of the integrated modeling and simulation concept, a metalworking process is used as a design example of a production system. Applied as a flow production of a single product, the manufacturing process is represented in four stages (Figure 7).
The process begins with casting and milling, while the third stage is the quality inspection. The quality inspection has the option to send faulty parts back to the milling unit again. The parts that qualify are packed and sent to the shipping buffer. Table 1 shows the process parameters for three different development cases (best/normal/worst). The development cases follow the idea of estimated process parameters, which are determined by a domain expert. The domain expert determines the three different states of the process parameters and their probability of occurrence.

By use of the process parameter, a discrete event simulation was run. The simulation took 2000 hours and 1100 orders were released. The model and the simulation experiment were created in GRAMOSA and transferred to the discrete event simulation environment. Three parameters with three different states were changed, which makes 27 possible permutations. The repetitions of each scenario were three runs, which can be noted in Figure 8. 
TABLE 1: Process parameters and the probability of occurrence in different development cases.

\begin{tabular}{lcccc}
\hline \multirow{2}{*}{ Process description } & Parameters & Costs $(€ / \mathrm{h})$ & Probability of occurrence $(\%)$ \\
\hline Casting & Processing time $(\mathrm{min})$ & Failure rate $(\%)$ & 350 & $(25 / 50 / 25)$ \\
Milling & 100 & $(8 / 10 / 15)$ & $(300 / 400 / 500)$ & $(15 / 65 / 20)$ \\
Quality inspection & 30 & 0 & 200 & $(15 / 80 / 5)$ \\
Packing & $(20 / 40 / 60)$ & 0 & 50 & - \\
Rework (milling) & 5 & 0 & 400 & - \\
\hline
\end{tabular}

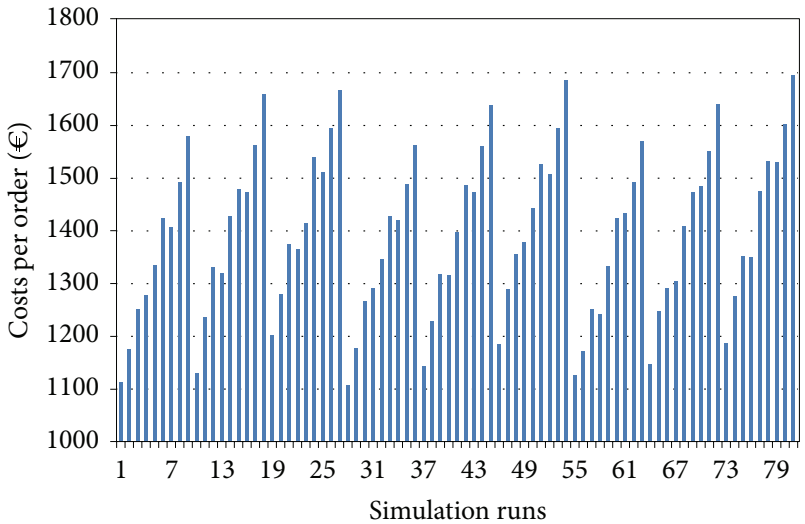

FIGURE 8: Simulation results.

\section{Risk-Based Allocation of Development Budget}

Based on the simulation results, a first statistical analysis can be made. It shows that the mean costs per order will amount to $1398,05 €$ (Figure 9). The following approach tries to optimize the allocation of the development budget in order to improve the mean value of costs per order.

The approach is based on the idea that the occurrence of best, normal, and worst case is not completely random. A specific management of development activities allows for shifting probabilities from worst to normal and from normal to best case. For example, the failure rate can be reduced by installation of a better SPC. The costs per hour will be reduced, if the process planner finds a cheaper vendor for the machine. The time for quality inspection will equally be reduced, if the work place is designed more economically. All this requires more time of the production system designer, which can be provided due to development budget.

\subsection{Problem Formulation}

\section{Parameters}

$P$ : Set of parameters, where $n=|P|$

$i$ : Index of the parameter $i \in[1, n]$

$C$ : Set of cases, where $m=|C|$ (a case can be worst case, normal, and best case)

$j$ : Index of case $j \in[1, m]$

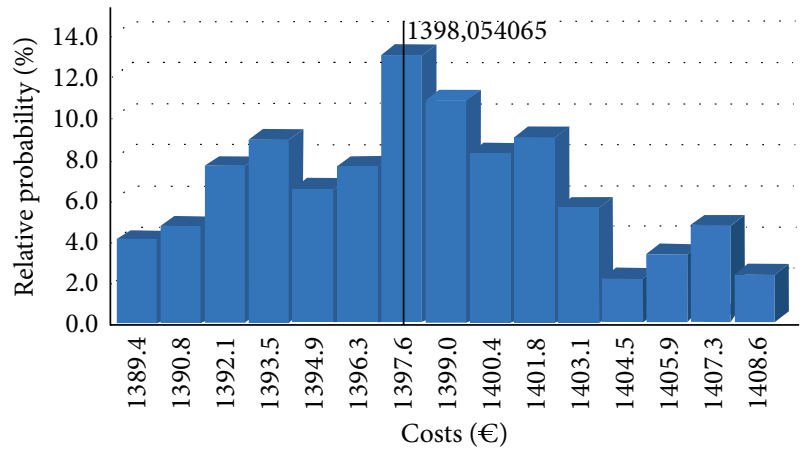

FIGURE 9: Statistical analysis of uncertainties in production system design.

$f_{i}$ : Impact changes factor of parameter $i$, where $f_{i}$ can either be positive or negative

$\operatorname{Prob}_{i j}^{n}$ : Probability occurrence of parameter $i$ in case $j$ in initial state

$\operatorname{Max}_{i}$ : Maximum limit of change allowed in $\%$ to the probability occurrence of parameter $i$

Cost $_{i}$ : Modification costs for each percent change to the probability occurrence of parameter $i$

$\operatorname{Exp}_{s_{k}}$ : Expected value of scenario $s_{k}$

DBudget: The total development budget.

Variables

$X_{i}$ : Change incurred into the probability occurrence of parameter $i$

$\operatorname{Prob}_{i j}^{o}$ : Probability occurrence of parameter $i$ in case $j$ in optimal state, which represents the positive or negative impact of the change $X_{i}$ of the initial probability occurrence $\operatorname{Prob}_{i j}^{n}$. $\operatorname{Prob}_{i j}^{o}=\operatorname{Prob}_{i j}^{n} f_{i} \cdot X_{i}$

$\Omega$ : Set of scenarios, where $S=|\Omega|$ and $S=i^{j}$. $\Omega$ represent all possible combination of different $\operatorname{Prob}_{i j}^{o}$ $s_{k}$ : Index of scenario of $\Omega$ and $k \in[1, S]$, where $s_{k}$ is an $i$-tuple, which denotes a possible combination of $\operatorname{Prob}_{i j}^{o} \forall i \in I$ and $\forall j \in J$. An example for $s_{k}$ is $\left(\operatorname{Prob}_{1 k}^{o}\right.$, $\left.\operatorname{Prob}_{2 k}^{o}, \ldots, \operatorname{Prob}_{i k}^{o}\right)$, and therefore there are $i^{j}$ possible combinations

$P\left(s_{k}\right)$ : Probability of scenario $s_{k}$, where $P\left(s_{k}\right) \prod_{i=1}^{n} s_{k i}$. 
TABle 2: Optimized allocation development budget.

\begin{tabular}{|c|c|c|c|c|c|c|c|}
\hline \multirow{2}{*}{ Process parameters } & \multicolumn{3}{|c|}{ Initial cases } & \multicolumn{3}{|c|}{ Optimized cases } & \multirow{2}{*}{ Development costs } \\
\hline & Worst case & Normal & Best case & Worst case & Normal & Best case & \\
\hline Casting failure rate & $25 \%$ & $50 \%$ & $25 \%$ & $0 \%$ & $25 \%$ & $75 \%$ & 100.000 \\
\hline Milling costs & $15 \%$ & $65 \%$ & $20 \%$ & $9 \%$ & $59 \%$ & $32 \%$ & 72.000 \\
\hline Quality inspection processing time & $15 \%$ & $80 \%$ & $5 \%$ & $15 \%$ & $80 \%$ & $6 \%$ & 3.000 \\
\hline
\end{tabular}

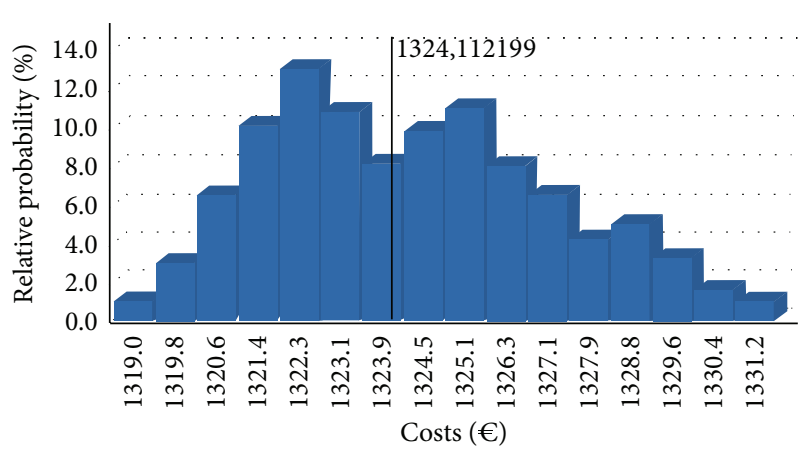

FIGURE 10: Statistical analysis by risk-optimized allocation of development budget.

Objective. The objective function is to minimize the mean value of costs per order.

$$
\min \sum_{k=1}^{S} P\left(s_{k}\right) \cdot \operatorname{Exp}_{s_{k}}
$$

Constraints. The objective function is subject to the following constraints:

$$
\begin{aligned}
& \forall i \in I \quad X_{i} \geq 0, \\
& \forall i \in I \quad X_{i} \leq \operatorname{Max}_{i}, \\
& \forall i \in I \quad \sum_{j=1}^{m} \operatorname{Prob}_{i j}^{o}=1, \\
& \forall i \in I \quad \sum_{i=1}^{n} X_{i} \cdot \text { Cost }_{i} \leq \text { DBudget. }
\end{aligned}
$$

Equation (2) ensures that the change to be incurred to the probability occurrence of parameter $i$ is positive and integer. Equation (3) guarantees that this change should not exceed a maximum value of change allowed in $\%$ to the probability occurrence of parameter $i$. Equation (4) indicates that the sum of the optimized probability occurrence of parameter $i$ in all cases $C$ is equal to $1(100 \%)$. Equation (5) restricts the optimized cost to be less than the total cost.

4.2. Experiment. The experiment is run by a development budget DBudget of $175000 €$. The modification costs Cost $_{1}$ of the casting failure rate are $2000 €$ per percent, while the modification costs Cost $_{2}$ of the milling costs are $6000 €$ per percent. The modification costs Cost $_{3}$ of the quality inspection processing time are $3000 €$ per percent. Table 2 shows the results of the optimized allocation of the development budget.

The statistical analysis of the optimized production development process shows mean costs of $1324,11 €$ per order (Figure 10), which is nearly $74 €$ less than that without the optimization.

\section{Conclusion}

New and existing production technologies are often not completely adoptable to new products. For this reason some of the main characteristics, like cost, time, or quality, have to be estimated at the beginning of process planning and production system development. In general, the estimations can be categorized into different probable cases, like best, normal, and worst case. These uncertainties can be considered in further production system design. In this paper the modeling concept GRAMOSA is applied and used for integrated planning and simulation in context of model driven logistics engineering. The simulations results are used and analyzed for the optimization of development risks in production system design. Thereby, a mathematical optimization problem is formulated, which seeks to minimize the mean costs per order by consideration of different uncertainties. The experiment shows promising results in regard to risk-optimized allocation of the development budget. To give an outlook, the approach will be extended to the performance measures of flexibility and productivity. Flexibility and productivity are important for production system design and are influenced by management actions. This is why they are promising factors for the presented approach of risk-optimized design of production systems.

\section{Conflict of Interests}

The authors declare that there is no conflict of interests regarding the publication of this paper.

\section{References}

[1] R. Riedel, D. Jentsch, S. Horbach, J. Ackermann, and E. Müller, "Agile planning processes," in Advances in Production Management Systems, vol. 414 of IFIP Advances in Information and Communication Technology, pp. 143-150, 2013.

[2] S. Dashkovskiy, H. R. Karimi, and M. Kosmykov, "Stability analysis of logistics networks with time-delays," Journal of Production Planning Control, vol. 24, no. 7, pp. 567-574, 2013. 
[3] H.-P. Wiendahl, H. A. ElMaraghy, P. Nyhuis et al., "Changeable manufacturing_classification, design and operation," CIRP Annals: Manufacturing Technology, vol. 56, no. 2, pp. 783-809, 2007.

[4] H. Mehrsai, R. Karimi, and B. Scholz-Reiter, "Application of learning pallets for real-time scheduling by the use of radial basis function network," Neurocomputing, vol. 101, pp. 82-93, 2013.

[5] B. Scholz-Reiter and M. Lütjen, "Modeling and evaluation of alternative production scenarios in the field of composite manufacturing," in Proceedings of the 20th European Modeling \& Simulation Symposium, R. Mosca, Ed., pp. 174-179, DIPTEM Universita di Genova, Campora S. Giovanni, Italy, 2008.

[6] M. Schenk, S. Wirth, and E. Müller, Factory Planning Manual: Situation-Driven Production Facility Planning, Springer, Berlin, Germany, 2010.

[7] M. Lauder, M. Schlereth, S. Rose, and A. Schürr, "Model-driven systems engineering: state-of-the-art and research challenges," Bulletin of the Polish Academy of Sciences: Technical Sciences, vol. 58, no. 3, pp. 409-421, 2010.

[8] C. Münster, Ein Beitrag zur Grobplanung von Lagersystemen Bei Ungewissen Planungsdaten, Technische Universität Brandenburg, 2004.

[9] A. Hassan, A. Siadat, J.-Y. Dantan, and P. Martin, "Conceptual process planning an improvement approach using QFD, FMEA, and ABC methods," Robotics and Computer-Integrated Manufacturing, vol. 26, no. 4, pp. 392-401, 2010.

[10] M. Bellgran and E. K. Säfsten, Production Development: Design and Operation of Production Systems, Springer, Berlin, Germany, 2010.

[11] S. Weig, Konzept eines integrierten risikomanagements für die ablauf- und strukturgestaltung in fabrikplanungsprojekten [Ph.D. Dissertation], TU München, 2008.

[12] R. R. Inman, D. E. Blumenfeld, N. Huang, J. Li, and J. Li, "Survey of recent advances on the interface between production system design and quality," IIE Transactions, vol. 45, no. 6, pp. 557-574, 2013.

[13] A. M. Kostin, G. Guillén-Gosálbez, F. D. Mele, M. J. Bagajewicz, and L. Jiménez, "Design and planning of infrastructures for bioethanol and sugar production under demand uncertainty," Chemical Engineering Research and Design, vol. 90, no. 3, pp. 359-376, 2012.

[14] J. Heilala, S. Vatanen, H. Tonteri et al., "Simulation-based sustainable manufacturing system design," in Proceedings of the Winter Simulation Conference (WSC '08), pp. 1922-1930, Miami, Fla, USA, 2008.

[15] K. K. B. Hon, "Performance and evaluation of manufacturing systems," CIRP Annals: Manufacturing Technology, vol. 54, no. 2, pp. 139-154, 2005.

[16] S. Dashkovskiy, H. R. Karimi, and M. Kosmykov, "A LyapunovRazumikhin approach for stability analysis of logistics networks with time-delays," International Journal of Systems Science, vol. 43, no. 5, pp. 845-853, 2012.

[17] B. Scholz-Reiter and M. Lütjen, "Production process engineering-modelling and evaluation of process chains for composite manufacturing," in Proceedings of the International Conference on Applied Production Technology, Production of Aircraft Structures (APT '07), pp. 43-51, BIAS, Bremen, Germany, 2007.

[18] S. Bergmann and S. Strassburger, "Challenges for the automatic generation of simulation models for production systems," in
Proceedings of the Summer Simulation Multiconference (SummerSim '10), pp. 545-549, Ottawa, Canada, July 2010.

[19] S. Horbach, "Implications of interoperability for factory planning," in Advances in Sustainable and Competitive Manufacturing Systems, Lecture Notes in Mechanical Engineering, pp. 379387, 2013

[20] R. Mueller, Specification and Automatic Generation of Simulation Models with Applications in Semiconductor Manufacturing, Georgia Institute of Technology, 2007.

[21] S. Straßburger, S. Bergmann, and H. Müller-Sommer, "Modellgenerierung im kontext der digitalen fabrik-stand der technik und herausforderungen," in Proceedings der 14 ASIMFachtagung Simulation in Produktion und Logistik, G. Zülch and P. Stock, Eds., pp. 37-44, KIT Scientific Publishing, Karlsruhe, Germany, 2010.

[22] L. Montrieux, Y. Yu, and M. Wermelinger, "Issues in representing domain-specific concerns in model- driven engineering," in Proceedings of the Workshop on Modeling in Software Engineering (ICSE '13), pp. 18-19, San Francisco, CA, USA, May 2013.

[23] D. C. Schmidt, "Guest editor's introduction: model-driven engineering," IEEE Computer, vol. 39, no. 2, pp. 25-31, 2006.

[24] M. Lütjen, Modellierungskonzept zur integrierten planung und simulation von produktionsszenarien entwickelt am beispiel der CFK-serienfertigung [Ph.D. thesis], University of Bremen, 2014, http://nbn-resolving.de/urn:nbn:de:gbv:46-00103681-13. 


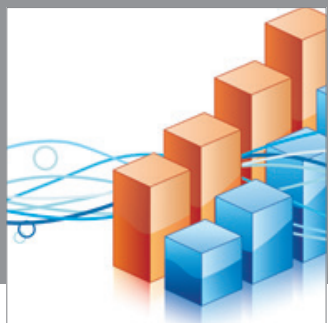

Advances in

Operations Research

mansans

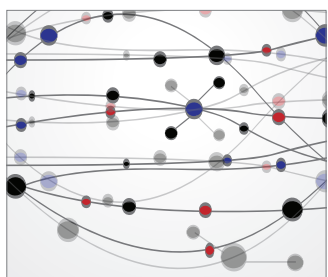

The Scientific World Journal
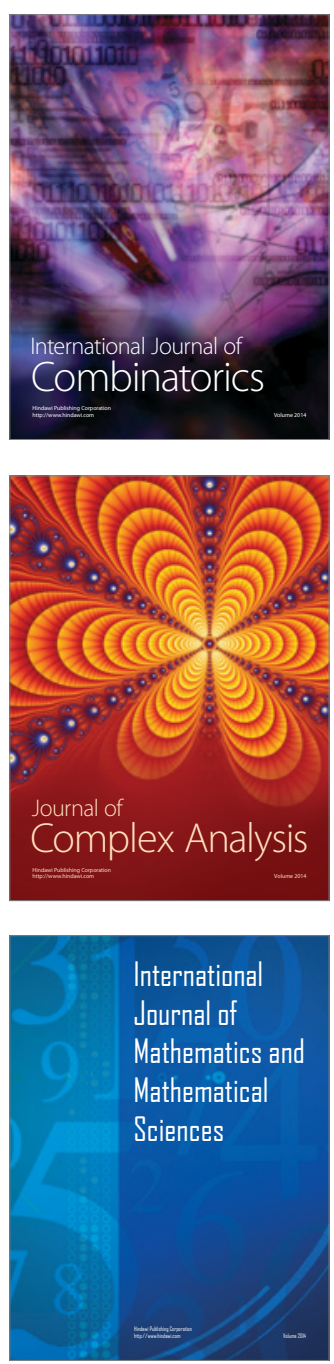
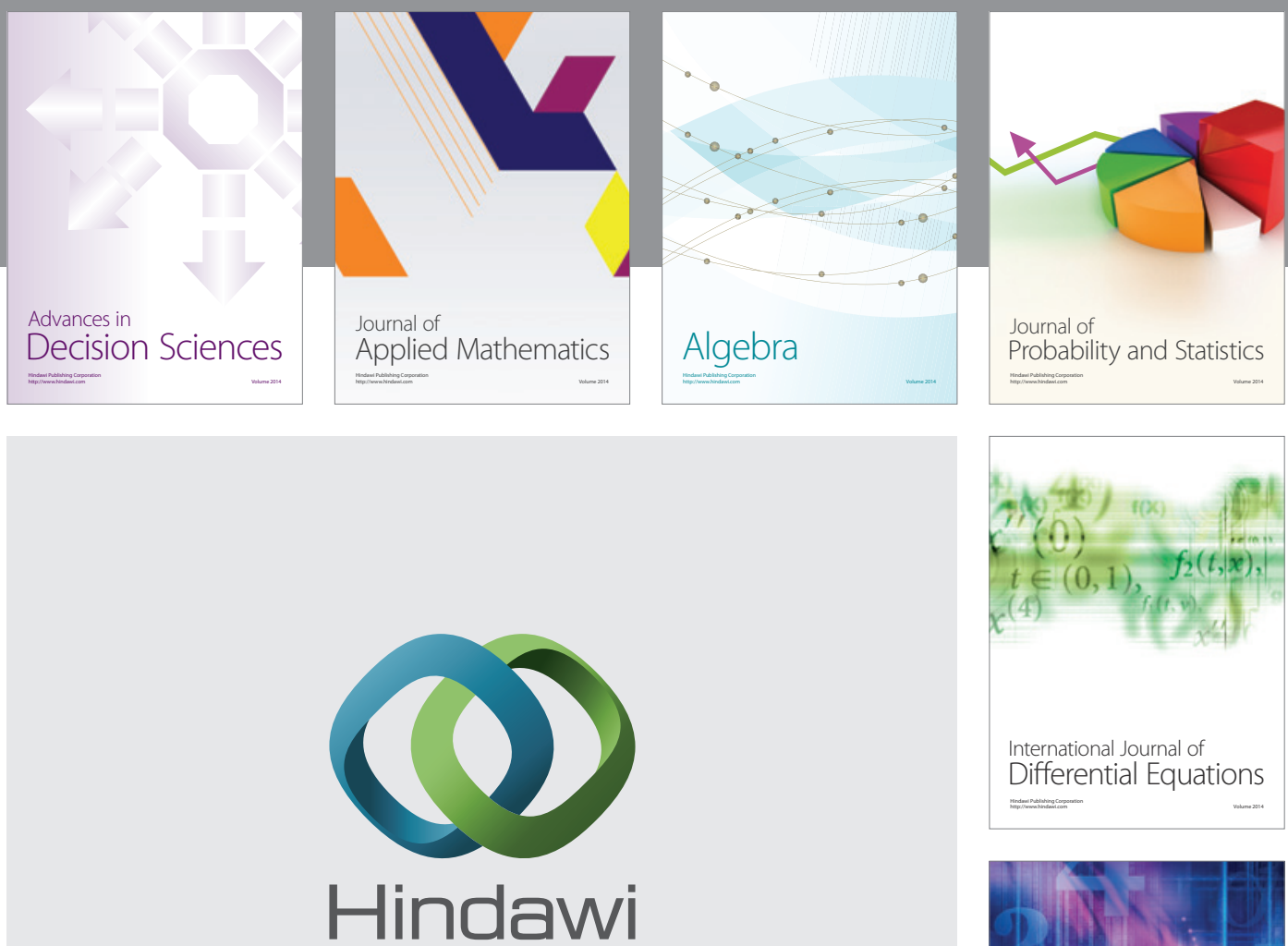

Submit your manuscripts at http://www.hindawi.com
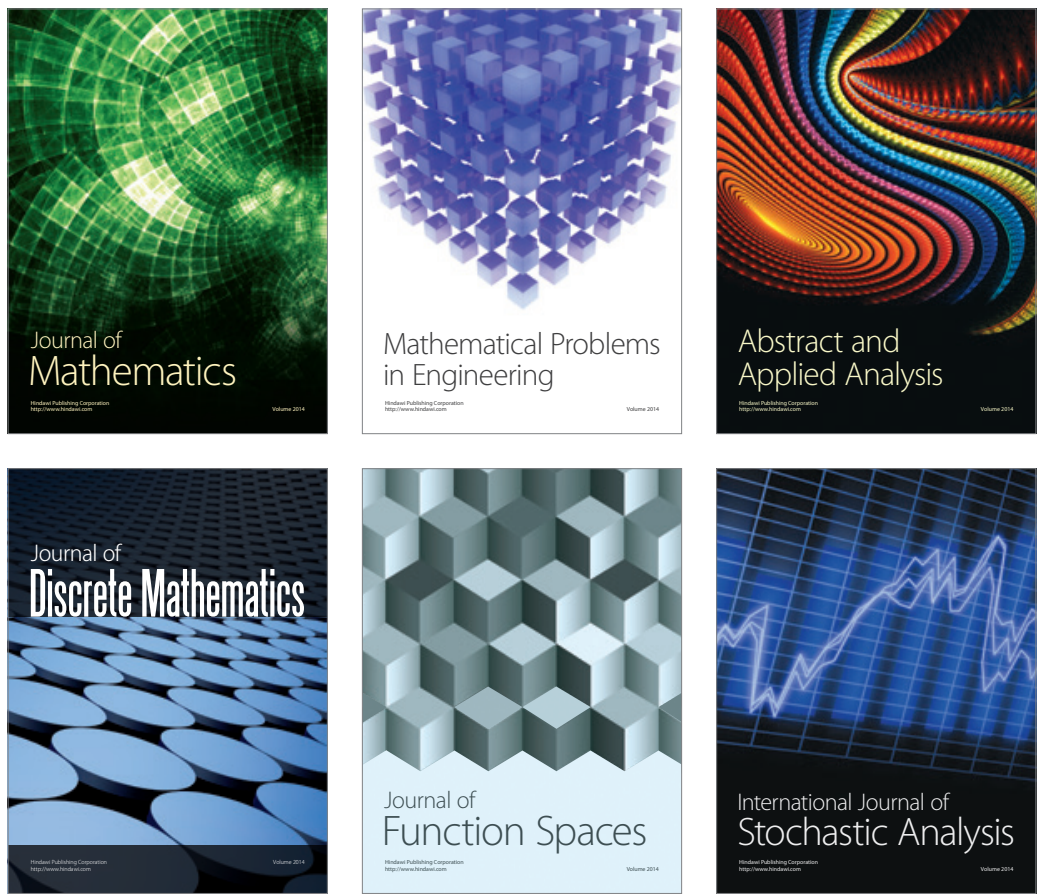

Journal of

Function Spaces

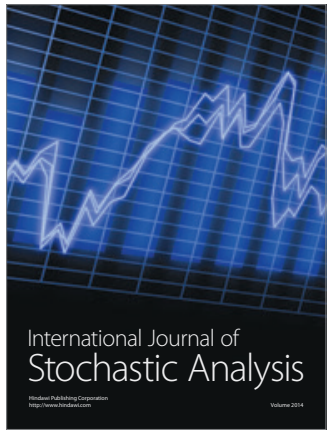

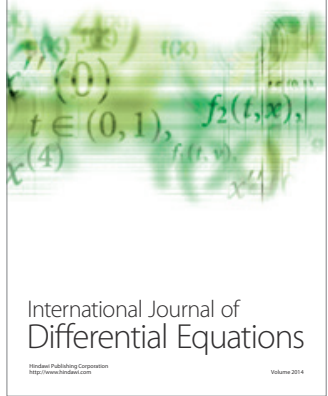
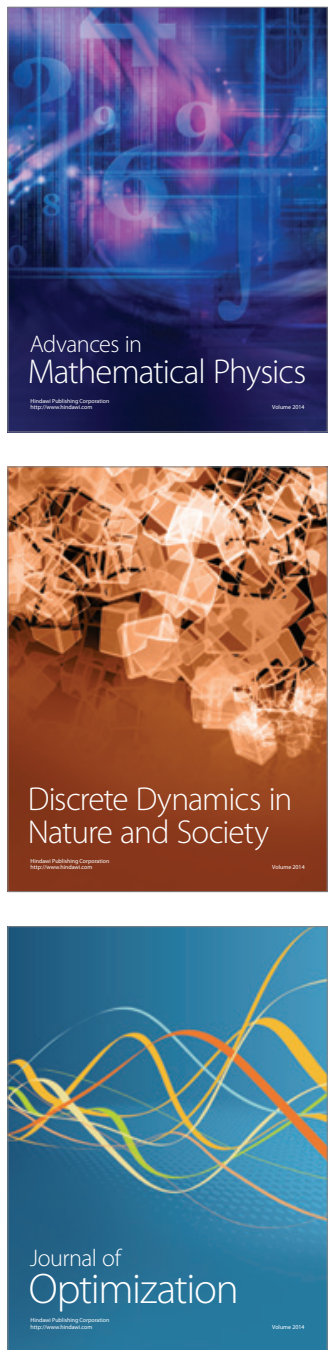